\title{
Reversible Inhibition of Tyrosine Protein Phosphatases by Redox Reactions
}

\author{
Daniela Cosentino-Gomes and José Roberto Meyer-Fernandes \\ Universidade Federal do Rio de Janeiro (UFRJ), \\ Instituto de Bioquímica Médica (IbqM) \\ Brazil
}

\section{Introduction}

Protein phosphorylation/dephosphorylation is considered a widespread mechanism of protein regulation. The covalent addition of a phosphate group to tyrosine residues in cellular proteins may occur as an appropriate response to a series of morphological and biochemical processes, with particular importance in complex functions such as growth, proliferation, differentiation, adhesion and motility. Protein tyrosine phosphorylation is regulated in the cell by the opposing activities of two classes of enzymes: protein tyrosine kinases, which phosphorylate specific tyrosine residues in protein using ATP as the phosphate source, and protein tyrosine phosphatases, which hydrolyze the phosphotyrosines yielding the restored amino acid residue and inorganic phosphate as products (Kolmodin \& Åqvist, 2001; Mayer, 2008). The number of active protein phosphatases with the ability to dephosphorylate phosphotyrosine are very similar to the number of active tyrosine phosphatases. Both types of enzymes also display comparable tissue distribution patterns (Alonso et al., 2004). Abnormalities in tyrosine phosphorylation play a role in the pathogenesis of numerous inherited and acquired human diseases from cancer to immune deficiencies (Alonso et al., 2004)

Phosphorylation, acetylation, ubiquitinylation and glycosylation are among the most wellknown post-translational modifications. The concept of protein oxidation as a posttranslational modification has only gained acceptance more recently. Protein oxidation occurs as an outcome of a chemical attack by reactive oxygen species (ROS) or reactive nitrogen species (RNS) on susceptible amino acids such as tyrosine, tryptophan, histidine, lysine, methionine, and cysteine (Spickett et al., 2006). Indeed, it is important to note that signal transduction must occur in a coordinated manner in response to a previous stimuli. The key elements of a signaling response is reversibility and specificity (Tonks, 2005). In this way, an oxidative-dependent chain reaction may be short and employ low concentration of oxidants to avoid irreversible damage to cellular components.

In this chapter, we will discuss the following: the structural mechanism of action of ROS in the enzymatic activity of tyrosine phosphatases and how it interacts with their target molecules; the reversible regulation of this enzyme by oxidants and antioxidants; and the major consequences of this tightly controlled mechanism on cell signaling. 


\section{Protein tyrosine phosphatases family}

The protein tyrosine phosphatase (PTP) superfamily is encoded by approximately 100 genes in the human genome. They all possess an overall structure with a core catalytic domain composed of four parallel $\beta$-strands surrounded on both sides by a-helices. The active site sequence $\operatorname{Cys}(X)_{5}$ Arg defines the PTP family, and this sequence is referred to as the "PTP signature motif". Moreover, this conserved motif creates a very similar structural motif, termed the PTP loop, which connects a central $\beta$-strand to an a -helix at the center of the catalytic site. The diversity within the families is conferred by the regulatory domains (Salmeen \& Barford, 2005; Tiganis \& Bennett, 2007). All protein tyrosine phosphatases are characterized by: a) their sensitivity to vanadate; b) an ability to hydrolyze the artificial substrate $p$-nitrophenyl phosphate; c) an insensitivity to okadaic acid; and d) a lack of metal ion dependence for catalysis (Chiarugi \& Buricchi, 2007; Denu \& Dixon, 1998). PTPs have the capacity to function both positively and negatively in the regulation of signal transduction, being able to stimulate or inhibit protein functions through their specific dephosphorylation activity (Tonks, 2006).

The protein tyrosine phosphatase superfamily can be grouped into two subfamilies, the tyrosine-specific phosphatases that comprise 38 different enzymes and the dual-specific phosphatases with 61 components in the human genome. The common classification of the protein tyrosine phosphatase family is depicted in table 1. Despite different subcellular localizations and substrate specificities, the protein tyrosine phosphatase classes employ a similar chemical mechanism for phosphate hydrolysis involving a transient cysteinylphosphate intermediate (Chiarugi et al., 2005; Östman et al., 2011).

\subsection{Protein tyrosine-specific phosphatases}

The subfamily of tyrosine-specific phosphatases is constituted by the well-known classical protein tyrosine phosphatase (PTP), which acts strictly on phosphotyrosine-containing proteins. The active site of this group is deeper than the catalytic site of dual-specific protein phosphatase, which makes these enzymes much more selective for p-Tyr-containing substrates than the dual-specific protein phosphatase. The classical PTPs can also be divided into transmembrane, receptor-like enzymes (RPTPs) and the cytosolic, nonreceptor PTPs (NRPTPs) (Chiarugi \& Buricchi, 2007).

\subsubsection{The receptor-like protein tyrosine phosphatases}

The receptor-like PTPs such as RPTPa and CD45 are cell-surface receptors and generally have an extracellular ligand-binding domain, a single transmembrane region, and one or two cytoplasmic catalytic domains. Receptor-like PTPs are mainly negatively regulated through dimerization, a known regulatory mechanism for many signal transduction molecules, such as receptor proteins (Chiarugi \& Buricchi, 2007). The number of PTP catalytic domains encoded by the human genome is greater than the number of PTP genes because many of the receptor-type proteins have tandem catalytic domains (Alonso et al., 2004). Receptor-like tyrosine phosphatases have the potential to regulate signaling through ligand-controlled protein tyrosine dephosphorylation. Many of these tyrosine phosphatases display features of cell-adhesion molecules in their extracellular segment and can be implicated in processes that involve cell-cell and cell-matrix contact (Tonks, 2006). 


\subsubsection{The intracellular protein tyrosine phosphatases}

The intracellular protein tyrosine phosphatases contain a single catalytic domain and various amino or carboxyl terminal extensions. They may contain SH2 (Src homology domain) domains that have targeting or regulatory functions, PEST (Pro-Glu-Ser-Thr domain) domains for proteolytic control, phosphorylation sites for protein/protein interactions, and enzymatic activity regulation. Cytosolic tyrosine phosphatases are characterized by regulatory sequences that flank the catalytic domain and control activity either directly, by interactions at the active site that modulate activity or by controlling substrate specificity. This class of enzymes is also activated through its own tyrosine phosphorylation, being essentially inactive under normal basal conditions. Among the members of this group are the prototype PTP1B, the most studied tyrosine phosphatase, the low molecular weight-PTP (LMW-PTP), and the Shp2 phosphatase (Alonso et al., 2004; Chiarugi \& Buricchi, 2007).

Tyrosine phosphorylation is common to all cytosolic enzymes, including those that do not contain an SH2 domain, such as PTP1B or LMW-PTP. Both phosphatases have been reported to be activated through autophosphorylation. At the same time, autodephosphorylation has been reported for several tyrosine phosphatases, including Shp2, RPTPa, Shp1, and LMW-PTP (den Hertog et al., 1994; Giannoni et al., 2005; Meng et al., 2002; Zhao et al., 1994). PTP1B action encompass numerous substrates, including different PTK receptors, such as the EGFR (epidermal growth factor receptor), PDGFR (platelet-derived growth factor receptor), CSF-1 (colony-stimulating factor 1), IR (insulin receptor) and IGF-1 (insulin-like growth factor-1) receptors, and cytoplasmic PTKs members, such as c-Src and JAK2 (Janus protein tyrosine kinase 2). The non-transmembrane Shp1 and Shp2 (protein tyrosine phosphatase Src homology 1/2 (SH2) containing domain) perform opposing tasks in signaling pathways. Shp1 , predominantly expressed in hematopoietic cells, is a negative regulator in the signaling pathways mediated by the chemokine and cytokine receptors and by other receptor tyrosine kinases. Unlike other tyrosine phosphatases that negatively regulate signaling, Shp2 phosphatases can positively regulate cell signaling through the dephosphorylation of substrates that are negatively regulated by tyrosine phosphorylation and can participate in the propagation of the ERK (extracellular-signal-regulated kinase) and PI3K (phosphoinositide 3kinase)/Akt (protein kinase B) pathways in which multiple receptor PTKs play a role (C. Y. Chen et al., 2009; Tiganis \& Bennett, 2007).

\subsection{The dual-specific tyrosine protein phosphatases}

The dual-specific protein phosphatases (DSPs) can dephosphorylate a variety of substrates, including phosphotyrosine-containing proteins, phosphothreonine, phosphoserine residues and phospholipids, and is the most diverse group in terms of substrate specificity because of this feature. The dual-specific protein phosphatases are much more diverse than tyrosinespecific phosphatases and can be divided into several subgroups. Eleven of the 61 dualspecific PTPs encoded by the human genome are specific for the mitogen-activated protein kinases (MAPK); the other ones can be represented by the well-known cell cycle regulators Cdc25 phosphatases and the tumor suppressor phosphatase (PTEN), which is also able to dephosphorylate lipid substrates (Alonso et al., 2004; Chiarugi \& Buricchi, 2007). The dualspecific tyrosine protein phosphatases also include the VH1-like enzymes, which are related to the prototypic VH1 DSP, a $20-\mathrm{kDa}$ protein that is a virulence factor of the vaccinia virus (Tonks, 2005). 
The MAPK phosphatases are characterized by dual phosphothreonine and phosphotyrosine specificity and the presence of a $\mathrm{CH} 2$ region and other MAPK-targeting motifs. They can dephosphorylate tyrosine and threonine residues within the activation loop of MAPKs. The different specificities towards the various MAPKs mean that MAPK phosphatase plays a critical negative regulation on the MAPK-mediated signaling process (Tiganis \& Bennett, 2007). Cdc25 phosphatases are involved in the dephosphorylation of cyclin-dependent kinases at their inhibitory, dually phosphorylated N-terminal Thr-Tyr-motifs. The reaction is required for activation of these kinases to drive progression of cell cycle (Alonso et al., 2004). Another subgroup of dual-specific protein phosphatases, the atypical dual-specific protein phosphatases, includes a number of poorly characterized enzymes that lack specific MAPKtargeting motifs and tend to be much smaller enzymes. This is the case for PIR (phosphatase interacting with RNA/RNP), which dephosphorylates mRNA. Cdc14 is involved in the inactivation of cyclin-dependent kinases and in exit from mitosis, while the slingshots and PRLs (phosphatase of regenerating liver) are poorly understood. PTEN dephosphorylates phosphatidylinositol-3,4,5-trisphosphate at the plasma membrane, while the myotubularins primarily dephosphorylate phosphatidylinositol-3-phosphate on internal surface of cell membranes (Alonso et al., 2004).

Regarding substrate specificity, dual-specific protein phosphatases may present a preference for either tyrosine or serine/threonine residues. For cyclin-dependent kinase (CDK)associated phosphatase (KAP), the phosphatase preferentially dephosphorylates the threonine residue in the activation loop of CDKs, while for the VH1-related dual-specific phosphatases, tyrosine is the preferred residue in MAPKs (Tonks, 2006).

\begin{tabular}{|c|c|c|c|c|}
\hline \multicolumn{3}{|c|}{ Classification } & PTPs & Ligand-inducing oxidation \\
\hline \multirow{12}{*}{$\begin{array}{c}\text { Protein } \\
\text { Tyorosine } \\
\text { Phosphatase } \\
\mathrm{C}(\mathrm{X})_{5} \mathrm{R}\end{array}$} & \multirow{7}{*}{$\begin{array}{l}\text { Tyrosine } \\
\text { specific } \\
\text { PTPs }\end{array}$} & \multirow{3}{*}{$\begin{array}{l}\text { Receptor } \\
\text { PTPs }\end{array}$} & PTPa & \\
\hline & & & PTPк & \\
\hline & & & CD45 & B-cell receptor stimulation \\
\hline & & \multirow{4}{*}{$\begin{array}{l}\text { Cytosolic } \\
\text { PTPs }\end{array}$} & Shp1 & B-cell receptor stimulation \\
\hline & & & Shp2 & $\begin{array}{c}\text { PDGF, T-cell receptor stimulation, } \\
\text { endothelin } 1\end{array}$ \\
\hline & & & PTP1B & $\mathrm{EGF}$, insulin \\
\hline & & & TCPTP & Insulin \\
\hline & \multirow{5}{*}{\multicolumn{2}{|c|}{ Dual specific PTPs }} & VHR & \\
\hline & & & MKPs & TNFa \\
\hline & & & LMW PTP & PDGF, integrin engagement \\
\hline & & & PTEN & PDGF, EGF, insulin \\
\hline & & & Cdc25 & \\
\hline
\end{tabular}

Table 1. Classification of the protein tyrosine phosphatase family and some of its principal members and ligand-inducing oxidation, according to Tonks in 2006. (PDGF, plateletderived growth factor; EGF, epidermal growth factor; TNFa, tumor-necrosis factor- $\alpha$; TCPTP, T-cell protein tyrosine phosphatase; MKP, mitogen-activated protein kinase phosphatase; LMW-PTP, low molecular weight protein tyrosine phosphatase). 


\section{Structural characteristics of the cysteine-based protein tyrosine phosphatase catalytic domain}

Protein tyrosine phosphatases are a family of enzymes with high structural multiplicity. Cysteine-based phosphatases share the common function of hydrolyzing phosphorester bonds in proteins and/or lipids via a conserved cysteine-based mechanism. The most significant feature of the protein tyrosine phosphatase superfamily is the presence of a signature motif $\operatorname{Cys}(X)_{5} \mathrm{Arg}$, where $X$ is any amino acid. This well-conserved motif forms the phosphate-binding loop in the active site, known as the P-loop or PTP-loop, and is responsible for structural features required for phosphate recognition and phosphorester hydrolysis. The structural arrangement ensures that the catalytic cysteine functions as the nucleophile in catalysis, which specifically binds negatively charged substrates, and the arginine, which is involved in phosphate binding, remains in close proximity to form a cradle to hold the phosphate group of the substrate in the correct place for nucleophilic attack (Chiarugi \& Buricchi, 2007; Salmeen \& Barford, 2005; Tabernero et al., 2008). Figure 1 shows the crystal structure of PTP1B complexed with phosphotyrosine.

A

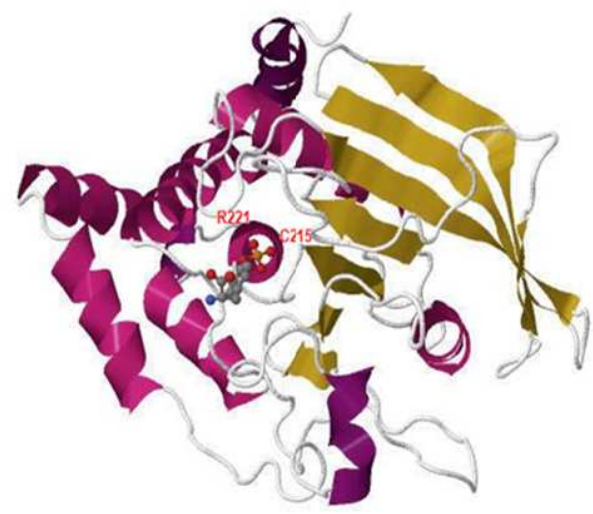

B

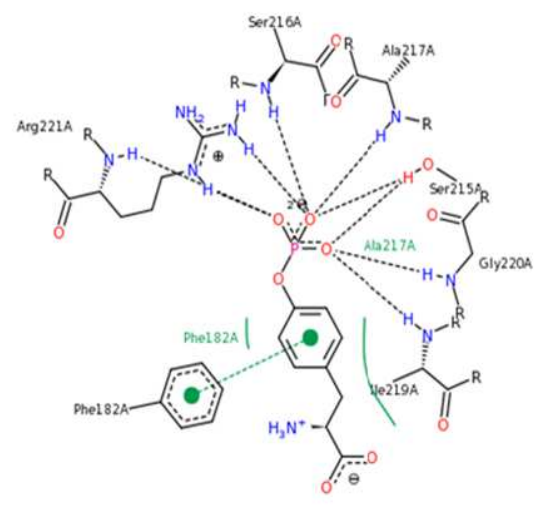

Fig. 1. (A) Crystal structure of PTP1B complexed with phosphotyrosine (PDB entry 1PTV) (Jia et al., 1995). A substrate positioned in the active site is represented by phosphotyrosine (ball and stick). The cysteine (C215) represented in the active site is the nucleophile that attacks the substrate phosphorous atom, forming the cysteinyl-phosphate intermediate. The arginine (R221) is involved in the intermediate stabilization and substrate binding (Tabernero et al., 2008). (B) Binding of phosphotyrosine to the catalytic site. Here the nucleophile cysteine 215 is mutated to serine 215 (Jia et al., 1995).

Specific protein tyrosine phosphatases utilize a two-step reaction for phosphate monoester hydrolysis (Fig. 2). The first step is initiated by a nucleophilic attack by the active-site cysteine (C215) on the phosphorus atom of the bound substrate that leads to the formation of a cysteinyl-phosphate intermediate. Besides substrate binding, the arginine is also involved in the stabilization of this intermediate. During the formation of the transition-state intermediate, the only aspartic residue in the WPD (Trp-Pro-Asp) loop acts as a general acid 
by donating its proton to the phenolic oxygen of the tyrosyl-leaving group, thus cleaving the phosphate of tyrosine to form the cysteine-phosphate intermediate. This first substitution reaction allows the phosphate group to be covalently attached to the nucleophile via a thioester linkage. In the second step of catalysis, the same aspartic residue functions as a general base by accepting a proton from water during hydrolysis of the cysteinyl phosphate intermediate, thus restoring the free enzyme to its normal basal Cys-SH conformation (Kolmodin \& Åqvist 2001; Tabernero et al., 2008; Tiganis \& Bennett, 2007). Figure 2 illustrates the general two-step catalysis of protein tyrosine phosphatases.

Most of the cysteine residues within proteins present a normal pKa of 8.3, and this characteristic ensures that this amino acid has a relatively good nucleophile attribute. Because of the unique environment of the tyrosine phosphatase active site, the catalytic cysteine presents an unusually low pKa value. Unlike the free cysteines, which are shown to be protonated at physiological $\mathrm{pH}$, the catalytic cysteines of the tyrosine-specific PTPs are more acidic and are therefore proposed to be deprotonated in the free enzymes at a physiological $\mathrm{pH}$ (or even at the $\mathrm{pH}$ optimum of 5-6), existing as a thiolate anion (Cys-S-). This property enables them to act as nucleophiles in the first step of catalysis but also makes them highly susceptible to oxidations by different reactive oxygen species and, to a lesser degree, with reactive nitrogen species. Exposure of thiolate anions to reactive nitrogen species causes S-nitrosothiol formation, whereas treatment with peroxynitrite yields Snitrothiol formation (Brandes et al., 2009; Chiarugi et al., 2005; Salmeen \& Barford, 2005).
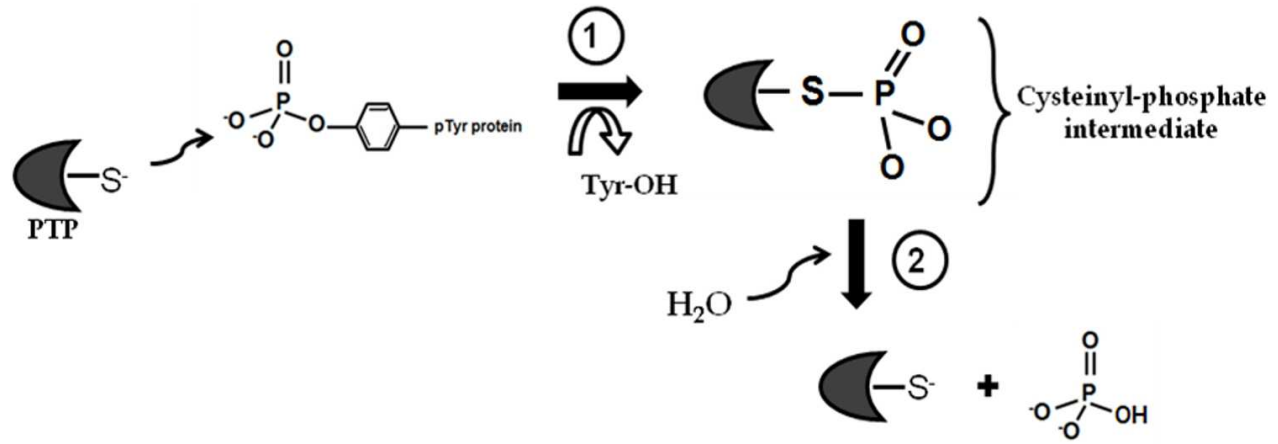

Fig. 2. Schematic mechanism of two-step catalysis of protein tyrosine phosphatases. The first step is initiated by a nucleophilic attack of the active site cysteine, which is in its thiolate anion conformation (Cys-S-), on the phosphorus atom of the bound substrate (1). The dephosphorylated protein tyrosine is released from the active site of the phosphatase while a cysteinyl-phosphate intermediate is formed. In the second step of catalysis, the aspartic residue in the P-loop accepts a proton from water during hydrolysis of the cysteinyl phosphate intermediate, thus restoring the free enzyme to its basal Cys-S- conformation (2).

After oxidation, the modified cysteine can no longer function as a phosphate acceptor in the first step of catalysis, which abrogates the catalytic function of tyrosine phosphatase (Chiarugi et al., 2005; Salmeen \& Barford, 2005). A network of hydrogen bonds stabilizes the negative charges in the active site. Among other interactions in the PTPs, it is found that the 
hydroxyl group of the serine or threonine residue in the signature motif is important for stabilizing the thiolate form of the active site cysteine, which results in the characteristically lower $\mathrm{pKa}$. The P-loop is found at the $\mathrm{N}$-terminus of an a-helix and should also contribute to the thiolate stabilization, as well as, the presence of neighbouring acid (Asp or Glu) and basic (Arg, His or Lys) amino acids near the catalytic cysteine (Hess et al., 2005; Kolmodin and Åqvist, 2001).

The structure of cytoplasmatic tyrosine phosphatases is highly conserved with only minor differences in the main structural core. The catalytic domain is formed by about 280 amino acids, which is responsible for the specific folding of the enzyme and other differing characteristics. The catalytic domain often exhibits relatively broad substrate specificities in vitro; however, under in vivo conditions, full-length tyrosine phosphatases have more stringent specificities. This is in part due to the presence of additional regulatory domains that direct their subcellular localization and interactions with specific substrates (Tabernero et al., 2008).

\section{Sources of oxidizing species in biological systems}

\subsection{Reactive oxygen species}

Reactive oxygen species (ROS) are a group of molecules produced in cells when oxygen is metabolized and are more reactive than molecular oxygen (Groeger et al., 2009). In aerobic organisms, ROS can originate from different sources, including mitochondrial electron transport chain, xanthine oxidase, myeloperoxidase, nicotinamide adenine dinucleotide phosphate (NADPH) oxidases (Nox enzymes), and lipoxygenase (Groeger et al., 2009; Östman et al., 2011; Salmeen \& Barford, 2005). The last two are responsible for the production of ROS in response to hormones, growth factors and cytokines (Bae et al., 1997; Salmeen \& Barford, 2005; Sundaresan et al., 1995). Among these oxygen metabolites are superoxide anions $\left(\mathrm{O}_{2}{ }^{\bullet-}\right)$, hydrogen peroxide $\left(\mathrm{H}_{2} \mathrm{O}_{2}\right)$ and hydroxyl radicals $(\cdot \mathrm{OH})(\mathrm{Chiarugi}$ $\&$ Buricchi, 2007). These species are not all equally reactive regarding to prospective targets. Many of them have very short half-lives, leading to little relevance in terms of signaling. For example, the hydroxyl radical is the most unstable radical, reflecting its limited ability to transmit signals across any significant distance. At the same time, superoxide and hydrogen peroxide can be considered more stable species and because of these, may be the most favorable ROS to operate as a signaling molecule (K. Chen et al., 2009).

After being considered important components of the biological process by McCord and Fridovich in 1969, free radicals emerged in the subsequent years as a dangerous byproduct of cellular metabolism by bringing deleterious consequences to DNA, lipids and proteins. The first research on reactive oxygen species has focused primarily on their chemical ability to react with and cause toxic and mutagenic effects on cellular components. There are exceptions, such as phagocytes, that deliberately generate reactive oxygen species as a main defense mechanism (Lambeth, 2002). Almost ten years later in 1977, Mittal and Murad showed the first evidence of the potential for free radicals to act in cellular signaling in metabolism. Now, it is largely accepted that living organisms have not only adapted to cope with oxidizing species but also have developed mechanisms for the advantageous use of free radicals (Dröge, 2002). ROS can act as second messengers that are required for the downstream signaling events (Cross \& Templeton, 2006) However, mechanisms by which 
proteins are able to sense ROS and translate signaling into an effective response are not totally clear.

Superoxide anions are derived by the univalent reduction of triplet-state molecular oxygen $\left(\mathrm{O}_{2}\right)$. This process is mediated by enzymes, such as xanthine oxidase, NADPH oxidases (Nox) and dual oxidases (Duox) (also known as Nox enzymes), or nonenzymatically by redox reactive compounds, such as the semi-ubiquinone of mitochondria. Within mitochondria, superoxide is continually generated as a result of electron leakage from the electron transport chain mainly at complex I (NADH/ubiquinone oxidoreductase) and complex III (ubiquinol/cytochrome c oxido-reductase) (Cross \& Templeton, 2006; Harrison, 2002).

\begin{tabular}{|c|c|c|}
\hline Nox Members & Expressing cells & Main characteristics \\
\hline Nox 1 & Colon, vascular smooth muscle, prostate & \multirow{3}{*}{$\begin{array}{l}\text { Similar to phagocytic Nox } 2 \\
\text { because of their structure and } \\
\text { enzymatic activity. }\end{array}$} \\
\hline Nox 3 & $\begin{array}{l}\text { Fetal liver, fetal lung, fetal spleen, fetal } \\
\text { kidney }\end{array}$ & \\
\hline Nox 4 & $\begin{array}{l}\text { Kidney, osteoclasts, pancreas, placenta, } \\
\text { skeletal muscle, ovary, astrocytes }\end{array}$ & \\
\hline Nox 5 & $\begin{array}{l}\text { Spleen, sperm, lymphnode, ovary, } \\
\text { placenta, pancreas }\end{array}$ & $\begin{array}{l}\text { Presents a calmodulin-like domain } \\
\text { and can be activated by calcium. }\end{array}$ \\
\hline Duox 1 & Thyroid, lung & \multirow{2}{*}{$\begin{array}{l}\text { Presents a calmodulin-like } \\
\text { domain, and an amino-terminal } \\
\text { peroxidase domain. }\end{array}$} \\
\hline Duox 2 & Thyroid, colon & \\
\hline
\end{tabular}

Table 2. Nox members in nonphagocytic cells.

Xanthine oxidase catalyzes the oxidation of xanthine to uric acid and $\mathrm{O}_{2}{ }^{\bullet}$. Further $\mathrm{O}_{2}{ }^{\bullet-}$ can be dismuted into hydrogen peroxide and molecular oxygen. The enzyme is expressed mainly in the liver and epithelia (Harrison, 2002).

Regarding the Nox family, seven mammalian members are known. The seven members are Nox1-5 and dual oxidases (Duoxs) 1 and 2. Nox proteins are integral membrane proteins with six transmembrane domains, which together are thought to form a channel to allow the successive transfer of electrons. They operate by transferring electrons from NADPH (converting it to $\mathrm{NADP}^{-}$) to $\mathrm{FAD}$, then to heme and finally to oxygen to make $\mathrm{O}_{2}{ }^{\circ-}$. Duox1 and 2 both have a peroxidase-like domain in their $\mathrm{N}$-terminal region, which means that these two members of the family produce hydrogen peroxide and not $\mathrm{O}_{2}{ }^{*}$ (Groeger et al., 2009). The NADPH oxidase complexes were firstly thought to be specific to macrophages, but now these enzymes are recognized and expressed almost universally in nonphagocytic cell types, and are also able to produce ROS via a similar mechanism (Chiarugi \& Buricchi, 2007; Cross \& Templeton, 2006). The wide-ranging distribution of Nox members, suggests that ROS production may have a broad implications for the different cellular phenotypes (K. Chen et al., 2009). Besides the NADPH oxidase from phagocytic cells (Nox 2), Nox family can be divided into three groups that present distinct regulatory patterns from those of Nox 2 . The 
three groups of nonphagocytic Nox members are summarized in table 2. The production of reactive species by NADPH oxidases occurs during inflammatory conditions in cells of the immune system or by external stimuli, such as growth factors in most mammalian cells, and their relevance is related to intracellular signaling (Dorgë, 2002; Lambeth, 2002).

Lipoxygenase is a mixed function oxidase involved in the synthesis of leukotrienes from arachidonic acids. Which are released from membrane phospholipids via the activity of cytosolic phospholipase $A_{2}$, and are also responsible for the production of superoxide (Chiarugi \& Buricchi, 2007; Kim et al., 2008).

Superoxide is not highly reactive and cannot cross cellular membranes; its diffusion is dependent of anion channels in the membranes. In most cases, the potential effects of superoxides are restricted to a single intracellular compartment that can be directed by some organelles like mitochondria, endosomes, and phagosomes (K. Chen et al., 2009). However, superoxide can readily be converted to hydrogen peroxide by superoxide dismutase, which finally penetrates membranes (Cross \& Templeton, 2006).

Hydrogen peroxide is a two-electron oxidant that acts as an electrophile and can react with protein thiol moieties to produce a variety of sulfur oxidation states, as will be discussed later. Most of the times, this reactivity affords reversible posttranslational modification of proteins that would be important for cellular signaling. Moreover, the relatively longer halflife of hydrogen peroxide compared with other ROS in biologic systems affords better activity as second messengers (K. Chen et al., 2009). Both, superoxide and hydrogen peroxide are involved in the inhibitory oxidation of the catalytic sites of the protein tyrosine phosphatases.

\subsection{Reactive nitrogen species}

The reactive nitrogen species $\left({ }^{\bullet} \mathrm{NO}\right)$ is produced in higher organisms by the oxidation of one of the terminal guanidino-nitrogen atoms of L-arginine. This process is catalyzed by the enzyme nitric oxide synthase (NOS). Nitric oxide (NO) can be generated by the reduction of $\mathrm{NO}_{x}$ species that are derived from exogenous or endogenous sources (Hess et al., 2005). Depending on the microenvironment, $\mathrm{NO}$ can be converted to various other reactive nitrogen species (RNS), such as nitrosonium cation $\left(\mathrm{NO}^{+}\right)$, nitroxyl anion $\left(\mathrm{NO}^{-}\right)$or peroxynitrite $\left(\mathrm{ONOO}^{-}\right)$(Dröge, 2002). Separate genes code for different NOS isoforms, for example, neuronal NOS (nNOS or NOS1) and for endothelial NOS (eNOS or NOS3), which are named after the tissues in which they were discovered, as well as, for inducible/ $\mathrm{Ca}^{2+}$-independent NOS (iNOS or NOS2). (Hess et al., 2005). Nitric oxide is produced in large amounts, ranging in nanomoles concentration, for several hours. In contrast, the constitutive NOS found in some tissues remains active for relatively short periods of time (Do et al., 1996). The attachment of the NO moiety to a nucleophilic group or a transition metal is called nitrosyl. Ingeneral, the NO moiety can be provided by NO itself, nitrite, other NOx species (higher NO oxides), metal-NO complexes. Nitric oxide has high reactivity for thiol groups that are present in proteins, reduced glutathione, or cysteine residues. The chemical addition of NO moiety to a reactive cysteine thiol group (nitrosation) is called S-nitrosylation (SNO). S-Nitrosylation-induced conformation can lead to the formation of S-nitrosoproteins, S-nitrosoglutathione, or Snitrosocysteine. These nitrosylated molecules can also serve as source of NO moieties. (Do et al., 1996; Janssen-Heininger et al., 2008). Accumulation of protein SNOs is the only mechanism 
of NO toxicity that is able to induce nitrosative stress. Nitrosative stress that results from increased or deregulated production of reactive nitrogen species is countered by several cellular mechanisms triggered by nitrosative modifications of proteins that mobilize adaptive and protective responses (Hess et al., 2005).

\subsection{Antioxidant mechanisms}

\subsubsection{Antioxidants of reactive oxygen species}

The transitory fluctuations in ROS provide important regulatory functions, but when present in high amounts, they can induce severe damage to cellular components. To avoid further deleterious outcomes, cells have evolved with the ability to handle increases in ROS production. These include various nonenzymatic and low-molecular-weight antioxidants, for example, reduced glutathione, vitamins A, C, and E, flavonoids, and enzymatic scavengers (Chiarugi \& Buricchi, 2007). Reduced glutathione is a tripeptide synthesized in cells by the sequential addition of cysteine to glutamate followed by the addition of glycine, giving rise to the molecular $\gamma$-L-glutamyl-L-cysteinyl-glycine. The sulfhydryl group (-SH) of the cysteine can be involved in reduction reaction, removing peroxides, or it can be associated in conjugation reactions with enzymes such as glutathione peroxidases (GPx) and the isoforme 6 of peroxiredoxins ( $\operatorname{Psdx} 6)$. These enzymes catalyze the reduction of hydrogen peroxide by GSH into $\mathrm{H}_{2} \mathrm{O}$ and oxidized glutathione (GSSG). In mammalian cells, GSH is present in millimolar concentrations and the conversion of GSH to its oxidized form GSSG by enzymatic activities serves as a redox buffer system within cells. The GSSG can then be reduced back originating two GSH molecules by the action of glutathione reductase enzymes, at the expense of NADH or NADPH (Cross \& Templeton, 2006; Forman et al., 2009). Glutathione also is important for maintaining ascorbate (vitamin c), itself a potent intracellular antioxidant, in a reduced state (K. Chen et al., 2009).

In cells, superoxide can be converted nonenzymatically to hydrogen peroxide and singlet oxygen $\left(\mathrm{O}_{2}\right)$, or through the enzymatic action of superoxide dismutases (SOD), superoxide can be then converted into $\mathrm{H}_{2} \mathrm{O}_{2}$, which is a less reactive specie. In mammals, three isoforms of superoxide dismutase are recognized: the cytoplasmatic SOD, which is a copper/zincdependent dismutase (SOD1); the mitochondrial manganese SOD (SOD 2); and the extracellular $\mathrm{Cu} / \mathrm{Zn}$-dependent SOD (SOD3).

In the presence of reduced transition metals, such as ferrous or cuprous ions, hydrogen peroxide can be converted into a highly reactive hydroxyl radical $\left(\mathrm{HO}^{-}\right)$. This radical is a less stable radical species and acts in a nonselective, oxidative manner on organic molecules. There are several families of enzymes, e.g., catalases, glutathione peroxidases (GPx), and peroxiredoxins (Prx), that break down hydrogen peroxide directly (Dröge, 2002; Salmeen \& Barford, 2005). Catalases are localized entirely in peroxisomes and efficiently converts hydrogen peroxide to water and molecular oxygen, while glutathione peroxidases are largely restricted to the cytosol and mitochondria. Glutathione peroxidases reduce peroxides by transferring electrons from GSH with the generation of oxidized glutathione. Peroxiredoxins exhibit a higher affinity toward hydrogen peroxide and are also abundant in the cytosol. Peroxiredoxins remove hydrogen peroxide to yield water, while form an intermolecular disulfide bond, which then can be reduced by thioredoxins (Trx). Consequently, thioredoxins are not directly involved in the removal of ROS, but indirectly 
through a supportive role to the peroxiredoxins. Besides their function as ROS scavengers, these enzymes can actually protect proteins from oxidations or regenerate oxidized proteins (K. Chen et al., 2009; Chiarugi \& Buricchi, 2007). The overall catalysis mechanism of these antioxidant enzymes is summarized below:

$$
\begin{aligned}
& \mathrm{O}_{2}^{\cdot-}+\mathrm{O}_{2}^{\cdot-}+2 \mathrm{H}^{+} \stackrel{\text { SOD }}{\longrightarrow} \mathrm{H}_{2} \mathrm{O}_{2}+\mathrm{O}_{2} \\
& \mathrm{H}_{2} \mathrm{O}_{2}+\mathrm{Fe}^{2+} \rightarrow \mathrm{Fe}^{3+}+{ }^{\bullet} \mathrm{OH}+\mathrm{OH}^{-}
\end{aligned}
$$

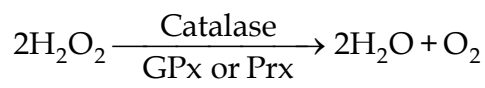

\subsubsection{Antioxidants of Nitrosylated Molecules}

As mentioned above nitrosative stress results from increased or deregulated production of reactive nitrogen species (Hess et al., 2005). The formation of S-nitrosoglutathione is regulated by the coordinately action of the enzyme S-nitrosoglutathione reductase (GSNO reductase), also known as glutathione-dependent formaldehyde dehydrogenase. This enzyme converts GSNO to GSNHOH, ultimately forming ammonia and oxidized glutathione. GSNO reductase is responsible for the regulation of the steady-state levels of Snitrosylated proteins, that are in equilibrium with GSH. Denitrosylation can also be achieved by specific metal ions, such as $\mathrm{Cu}^{+}$, the low-molecular-weight antioxidant ascorbate, or thioredoxins enzymes (Janssen-Heininger et al., 2008).

\section{Redox inhibition of cysteine-based protein tyrosine phosphatases}

Reversible oxidation of regulatory proteins by hydrogen peroxide or NO/SNO has been implicated in broad cellular signaling mechanisms. Tyrosine phosphatases can be differentially regulated by phosphorylation, intra- and intermolecular interactions, alternative splicing, transcription, and translation, but recently, it has become apparent that this family of enzymes may also be regulated by reversible oxidation. In general, the redox regulation of proteins occurs primarily when cysteine residues within the protein or bound to transition metals react with ROS, such as $\mathrm{H}_{2} \mathrm{O}_{2}$ or superoxide, or with reactive nitrogen species, such as nitric oxide, $S$-nitrosothiols, or peroxynitrite. Reactions of cysteines with mild oxidizing or nitrosylating reagents, such as low concentrations of $\mathrm{H}_{2} \mathrm{O}_{2}$ or $\cdot \mathrm{NO}$, can lead to reversible modulations of protein activity. Oxidation or nitrosylation of the catalytic cysteine of protein tyrosine phosphatases renders the residue unable to act as a nucleophile, and the enzyme loses its phosphatase activity (Chiarugi et al., 2005). Protein phosphatases are among the earliest characterized targets of inhibition by thiol group modification. Thiol group modifications are thought to play a central role in cellular signaling process through ROS modifications (Cross \& Templeton, 2006).

The first evidence of protein regulation by the redox modulation of a cysteine was described in 1967 by Pontremoli and colleagues, which showed that disulfide formation with cysteamine stimulated fructose-1,6-bisphosphatase activity. The redox regulation of tyrosine phosphatases depends on different oxidative stress conditions and is tissue specific (Chiarugi et al., 2005). 


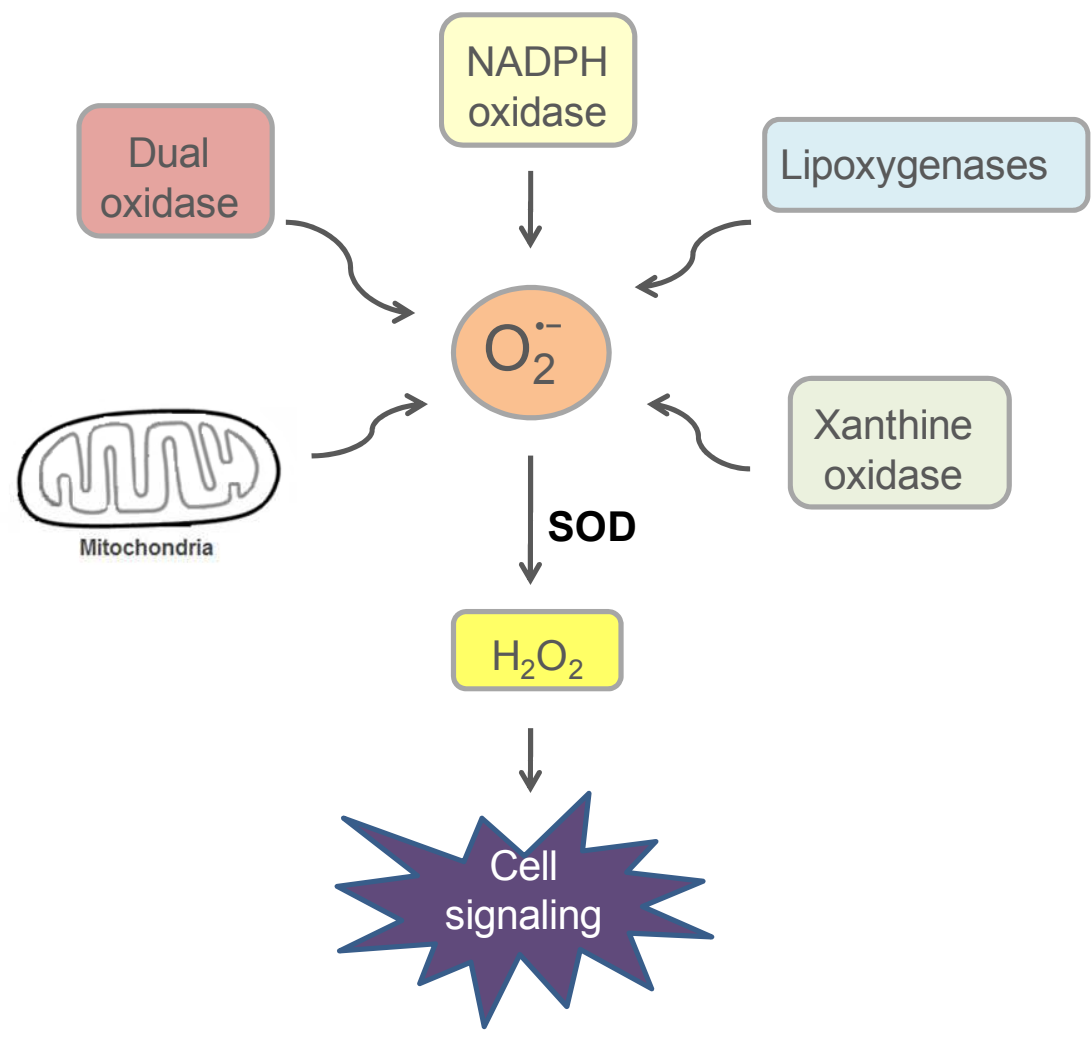

Fig. 3. Sources of reactive oxygen species. Superoxide $\left(\mathrm{O}_{2}{ }^{-}\right)$can be produced from different sources as within the mitochondrial electron transport chain, the activity of xanthine oxidases, Nox members like NADPH oxidase or Dual oxidase, and lipoxygenases. Later, superoxide may be dismuted to hydrogen peroxide $\left(\mathrm{H}_{2} \mathrm{O}_{2}\right)$ through the action of superoxide dismutase (SOD). $\mathrm{H}_{2} \mathrm{O}_{2}$ can then act as second messenger in cell signaling.

For tyrosine phosphatases, the typical element of redox regulation occurs within the catalytic site of the enzyme. Two specific amino acid residues are essential to the catalysis of tyrosine phosphatases, Cys215 and Arg221. Oxidation of the catalytic cysteine of the protein tyrosine phosphatases occurs in vivo in response to intracellular ROS production, which can occur in response to a variety of stimuli, such as platelet-derivative growth factor (PDGF), epidermal growth factor (EGF), insulin, several other cytokines, and integrins (Rhee et al., 2003; Tonks, 2005). Cysteine residues are also affected by extracellularly added ROS or by an imbalance of the redox potential within the cell. Therefore, hydrogen peroxide, Snitrosylation, or other radical species may oxidize cysteine residues in proteins to form cysteine sulfenic acid (Cys-SOH), which can be further stabilized by the formation of interor intramolecular disulfide (S-S) or sulfenyl-amide bonds. The last conformation is characterized by a five-membered ring that is formed by the covalent linkage of an atom of the catalytic cysteine to an amide nitrogen in a neighboring residue (Chiarugi \& Buricchi, 2007; Denu \& Tanner, 1998; Janssen-Heininger et al., 2008). 
Different cysteine residues can take part in the disulfide bridge, such as what may occur with the catalytic cysteine of LMW-PTP or PTEN with another cysteine residue or between the classical protein tyrosine phosphatases such as PTP1B and a cysteine from GSH (Barrett et al., 1999; Chiarugi et al., 2001; den Hertog et al., 2005; Kwon et al., 2004; Lee et al., 1998; Salmeen \& Barford, 2005). The tripeptide GSH can also induce alterations of proteins function by the formation of mixed disulfide bonds, a reversible process referred to as glutathionylation. The last conformation can result in a temporarily inhibition of PTP activity that protects enzyme from irreversible oxidation. Glutathionylation can be easily reversed by the action of glutaredoxins or thioredoxins, restoring normal enzyme function (Cross \& Templeton, 2006).

It is assumed that both disulfide bonds or sulfenyl-amide conformations protect the reactive cysteine from a higher-order, irreversible oxidation or expose the oxidized cysteine to cellular reducing agents, which facilitates the reactivation of the oxidized cysteine, because sulfenyl-amide rings or disulfide bonds represent reversibly oxidized states of cysteine and can be readily reduced (Chiarugi et al., 2005; Salmeen \& Barford, 2005; Tonks, 2005; Tabernero et al., 2008). Moreover, these two conformational changes may represent a signal that the given protein tyrosine phosphatase is in a temporarily inactive state (Tabernero et al., 2008), which may be important to stabilize associations within protein complexes, to modify structures, to create, destroy or modulate functional sites, or to regulate enzymatic or transcriptional activities of proteins (Poole \& Nelson, 2008).

Dual-specific phosphatases, such as Cdc25, PTEN, and LMW-PTP, and classical protein tyrosine phosphatases are also a target of ROS oxidation. Nevertheless, these enzymes contain a second cysteine residue within the active site. Following oxidation of the cysteine in the signature motif, a disulfide bond is formed with the vicinal cysteine, which protects the enzyme from higher oxidation and irreversible inactivation. Intramolecular disulfide bond formation involving the catalytic cysteine of classical PTPs has not been observed (den Hertog et al., 2005; Lee et al., 2002; Tonks, 2005).

Different phosphatases present distinct sensitivities to oxidation. Regulation of the oxidized states of the cysteine may vary with the structural distances between the cysteines involved in the formation of disulfide bridge and the availability of thiolate ions. This may represent a degree of specificity for protein tyrosine phosphatase redox regulation and lead to a different extent of oxidation (Chiarugi \& Buricchi, 2007).

Inactivation of the protein tyrosine phosphatases by hydrogen peroxide could be reversed by thiol-reducing agents such as dithiothreitol (DTT), $\beta$-mercaptoethanol, reduced glutathione, cysteine or by the action of some enzymes in which their catalytic cycle involves either a mono- or dithiol mechanism, such as glutaredoxins, thioredoxins, and protein disulfide-isomerase that have a CXXC motif in the active site. Thioredoxins are able to reduce sulfenic acids and disulfide bonds, while glutaredoxins are involved in the reversibility of mixed disulfides with GSH and S-nitrosothiols (Chiarugi \& Buricchi, 2007).

The oxidative modification of protein tyrosine phosphatases can be stable over prolonged periods (Salmeen and Barford, 2005). In some cases, the sulfhydryl group is open to further irreversible oxidation if no cysteine derivatives or compounds containing thiol groups are close enough to facilitate the formation of a disulfide bridge or a sulfenyl-amide ring. The addition of one or two oxygen molecules results in the formation of sulfinic acid $\left(\mathrm{Cys}-\mathrm{SO}_{2}\right)$ 
or sulfonic acid $\left(\mathrm{Cys}-\mathrm{SO}_{3}\right)$, respectively. These oxidative modifications are irreversible, and the phosphatase will be unable to become active again, even in a reducing environment (Groeger et al., 2009). However, it has been shown recently that sulfinic acids can be reduced by the action of a specific enzyme called sulfiredoxin, which has only been described in mammals and yeast so far (Biteau et al., 2003; Woo et al., 2003).

The redox balance of the cells can affect the ability of ROS to oxidize a given protein. At normal cellular conditions, the cellular redox potential may vary from $-260 \mathrm{mV}$ to $-150 \mathrm{mV}$. In addition, protein oxidation will depend on the distance between the site of ROS production and the target protein and on the concentration of scavenger enzymes available. The length of time that the protein will be inactivated will also depend on the proximity to enzymes such as glutaredoxin and thioredoxin, which catalyze thiol reduction (Salmeen \& Barford, 2005). Regarding protein tyrosine phosphatases, the differences in pKa values of catalytic cysteines, the availability of thiolate ions and the structural distance between the two cysteines involved in the disulfide bridge may also strongly determine the ability of the phosphatases to be rapidly regulated by changes in the intracellular redox conditions, thereby representing a degree of specificity for tyrosine phosphatase regulation (Chiarugi et al., 2005).

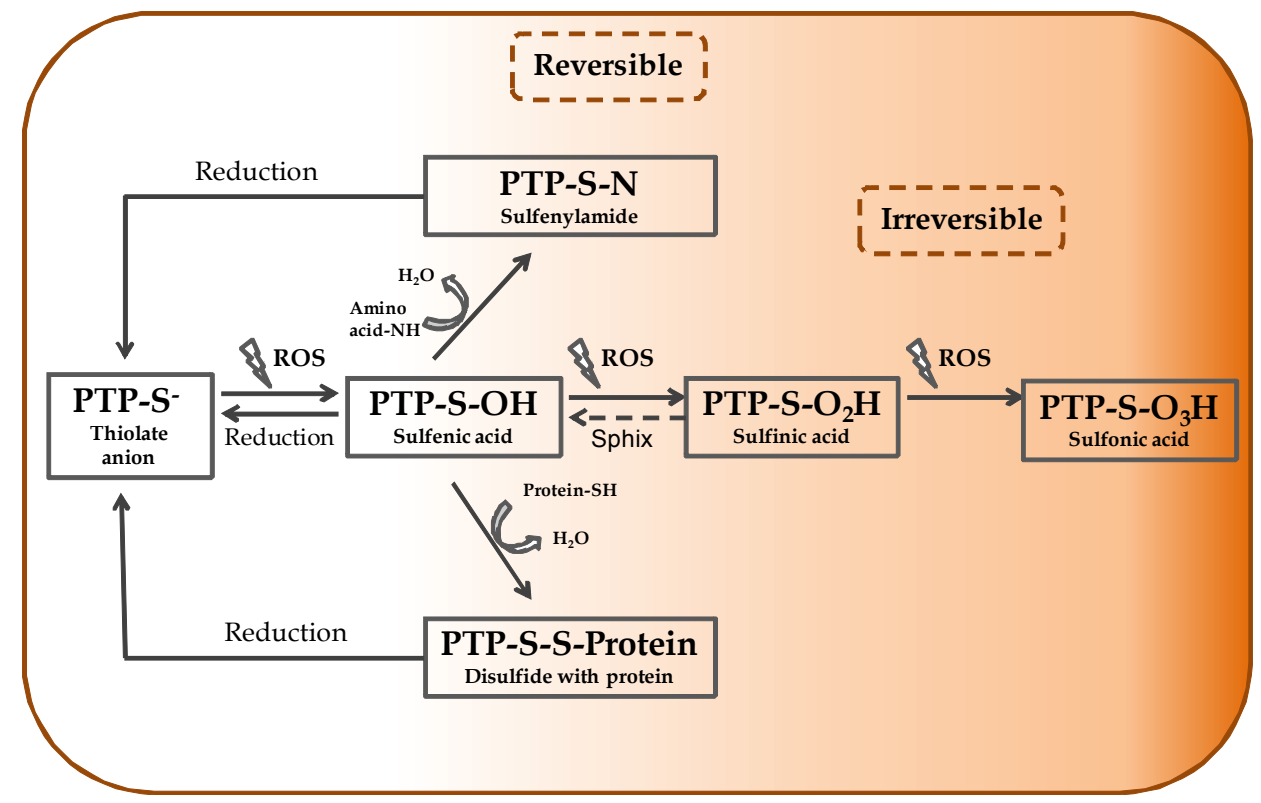

Fig. 4. The redox modulation of a protein tyrosine phosphatase thiolate anion. Because of its low $\mathrm{pKa}$ value, the cysteine residue in the active site of the tyrosine phosphatase is present in its thiolate anion form. This conformation facilitates the inhibition of the enzyme by oxidation, which would become inactivated as the sulfenic acid form. Furthermore, sulfenic acid is converted to a more stable conformation, such as a disulfide bridge or sulfenyl-amide ring. Both conformations are stable and reversible through the action of reductant agents. However, if oxidation persists for a long period, stronger and higher oxidation could lead to the formation of sulfinic and sulfonic acids, which are irreversible conformations. In some cases, sulfinic acid can be reversed enzymatically through the action of sulfiredoxin (Sphix) enzyme. 


\section{Cellular signaling through oxidative inhibition of the protein tyrosine phosphatases}

\subsection{Receptor tyrosine kinases}

Cellular signaling processes are controlled by the coordinated activity of protein phosphatases and kinases. Protein tyrosine kinases (PTKs) are usually divided into two families, the transmembrane receptor family and the nonreceptor family (Blume-Jensen \& Hunter, 2001). Receptor tyrosine kinases (RTKs) are cell-surface, transmembrane receptors carrying a multidomain extracellular segment that binds polypeptide ligands, a single-pass transmembrane helix, and a cytoplasmic segment containing a tyrosine kinase domain together with several regulatory sequences located both $\mathrm{N}$ - and C-terminal to the kinase domain. The receptor tyrosine kinase family includes epidermal growth factor receptor (PDGFR), fibroblast growth factor receptor (FGFR), and the insulin receptor kinase (IRK), among others (Chiarugi \& Buricchi, 2007).

The kinase activities of protein tyrosine kinases are closely regulated through autoregulatory mechanisms and by the action of tyrosine phosphatases. In general, most tyrosine kinases are maintained in a low activity state through a variety of these autoregulatory mechanisms and by avoiding the most favorable configuration of the kinase active site. Activation of receptor tyrosine kinases is achieved through a ligand binding to the extracellular domain, which stabilizes a dimeric receptor arrangement and facilitates trans-phosphorylation in the cytoplasmic domain. Autophosphorylation of one or two conserved tyrosines within the juxtamembrane domain of these receptors is required for complete kinase activation (Chiarugi \& Buricchi, 2007).

\subsection{Hydrogen peroxide as a second messenger in cellular signaling}

The classic receptor-mediated signaling involves a ligand engagement, followed by the production of a diffusible second messenger that interacts with a target to affect the signal. This arrangement supports both signal transduction over space and signal amplification, because most second messengers are produced via an enzymatic process. Typically, second messengers are small, diffusible molecules that rapidly activate effector proteins such as protein kinases, phosphatases or ion channels. These molecules can act through binding or chemical modification, thus promoting signal transduction (K. Chen et al., 2009).

It is now widely accepted that hydrogen peroxide may function as a second messenger within cells by being able to induce tyrosine phosphorylation of cellular proteins, which is strongly potentiated by a combination treatment with vanadate. The mechanism was believed to be attributed to the inhibition of tyrosine phosphatase, the activation of tyrosine kinases, or both (Chiarugi \& Buricchi, 2007). Furthermore, the addition of exogenous hydrogen peroxide to cells can mimic the effects of growth factors or hormones and lead to hyperphosphorylation of receptor tyrosine kinases. Mitogen-activated protein kinases have also been shown to be activated by extracellular hydrogen peroxide through a specific kinase cascade (Torres, 2003).

Little is known about how hydrogen peroxide is actually distributed to the cytoplasm. Most of the time, Nox family members are responsible for producing hydrogen peroxide near the receptor at the plasma membrane; in addition, hydrogen peroxide, which is produced in 
response to stimulation by a ligand, is released outside of the cell to then be diffused locally into the cell. Also, NADPH oxidase and lipoxygenase, which can be localized within the endoplasmic reticulum and the nuclear membrane, are able to release hydrogen peroxide into the luminal spaces of the specific organelles (Chiarugi \& Buricchi, 2007; Tonks, 2005).

Until recently, it was thought that hydrogen peroxide would cross biological membranes freely; however, many membranes were shown to be almost impermeable to hydrogen peroxide as well as to water (Antunes \& Cadenas, 2000; Makino et al., 2004; Seaver \& Imlay, 2001). Thus, for transport, hydrogen peroxide must be carried by an appropriate transporter that has not yet been well characterized (Chiarugi \& Buricchi, 2007).

\subsection{Nitric oxide as a second messenger in cellular signaling}

Nitric oxide is a gas, which readily diffuses across membranes and does not act at conventional membrane associated receptors (Do et al., 1996). Like hydrogen peroxide, signal transduction through induced-nitric-oxide modifications relies on the system of Cysbased posttranslational modifications. Accordingly, S-nitrosylation of proteins plays an essential role in downstream cascades.

Nitric oxide exerts a ubiquitous influence on cellular signaling in large part by means of Snitrosylation/denitrosylation of protein cysteine residues. SNO, or higher oxides is considered a post-translational protein modification that is precisely regulated, conferring specificity to NO-derived effects. These NO-dependent modifications influence protein activity, protein-protein interactions, and protein location. S-nitrosylation thus serves as the prototypical redox-based signal (Janssen-Heininger et al., 2008).

S-Nitrosylation has been implicated in transmitting signals downstream of all classes of receptors, including G-protein-coupled receptor (GPCR), receptor tyrosine kinase, tumor necrosis factor, Toll-receptors, and glutaminergic receptors, acting locally within subcellular signaling domains as well conveying signals from the cell surface to intracellular compartments, including the mitochondria and the nucleus (Janssen-Heininger et al., 2008).

Regarding cellular signaling through S-nitrosylation, specific features of this kind of modification can be considered useful tools in signaling transduction According to JanssenHeininger et al. (2008). These features include:

1. Temporal regulation of response through a rapid and controlled stimulation;

2. The existence of motifs within proteins that provides S-nitrosylation specificity;

3. Colocalization of target proteins with a source of NO;

4. Reversibility of protein S-nitrosylation;

5. Enzymatic control of S-nitrosylation through the action of S-nitrosoglutathione reductase.

\subsection{The role of protein tyrosine phosphatases in cellular signaling}

Physiological stimuli, such as growth factors or the engagement of antigen receptors, can trigger localized and controlled production of ROS. Protein tyrosine phosphatases, because of their high susceptibility to inactivation by oxidation at physiological $\mathrm{pH}$, are targets of ligand-induced ROS generation. Thus, the ability of tyrosine phosphatases to 
dephosphorylate receptor tyrosine kinases becomes temporarily compromised because of the oxidation of the catalytic site of the tyrosine phosphatases. These events are involved in the enhancement of the signaling response through an overall increase in tyrosine phosphorylation. Therefore, complete activation of the tyrosine kinase signaling cascades requires both an inhibition of protein tyrosine phosphatases by oxidation and an activation of receptor tyrosine kinases by phosphorylation (Salmeen \& Barford, 2005). Redox signaling through the reversible oxidation of tyrosine protein phosphatases must occur through a reaction that is chemically reversible under physiological conditions to ensure the continuity of cellular mechanisms.

\section{1-Signaling initiation}

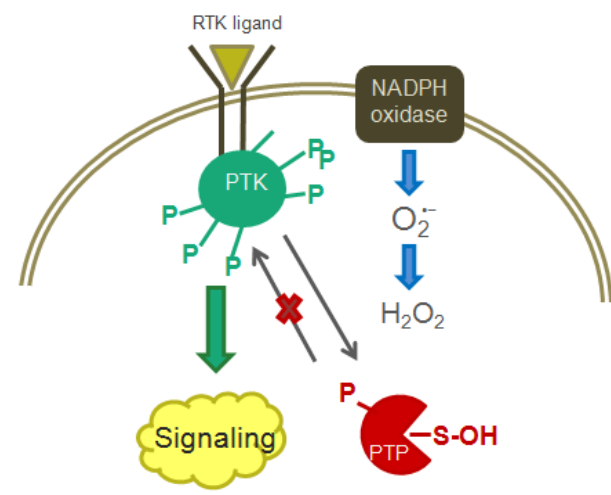

\section{2- Signaling termination}

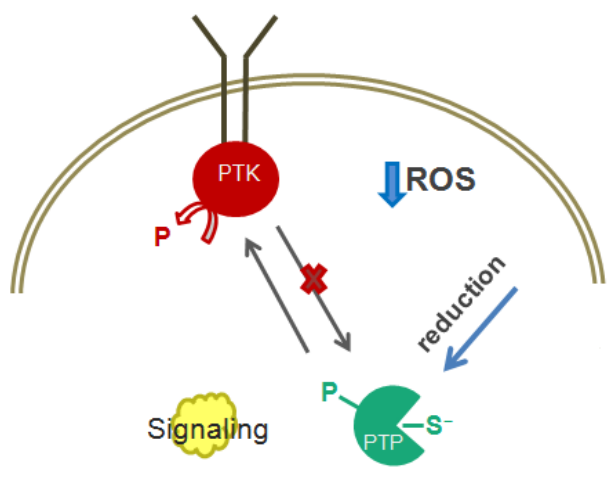

Fig. 5. After ligand engagement, the receptor tyrosine kinase (RTK) needs the first phase in which the tyrosine phosphorylation level must be high to guarantee signal propagation. This high level is granted by a transient inhibition of protein tyrosine phosphatase (PTP) due to oxidation promoted by hydrogen peroxide and by the disrupted association with the receptor substrates. Hydrogen peroxide is produced by NADPH oxidase that also became activated by ligand stimulation of the receptor tyrosine kinase. The concomitant tyrosine phosphorylation of oxidized protein tyrosine phosphatase, which is performed in response to receptor tyrosine kinase activation, is ineffective on the abolished enzymatic activity and preparative for the second phase. In the signaling termination phase, the tyrosine phosphatase recovers its enzymatic activity due to a re-reduction of the catalytic thiol group and immediately becomes hyperactive due to the previous tyrosine phosphorylation, thus promoting the rapid and efficient termination of the signal. The tyrosine phosphatase recurrence after oxidation is followed by a dephosphorylation of the activated receptors, which consequently terminates the signal (Chiarugi et al., 2005).

Besides their regulatory functions, the regulatory domains in tyrosine phosphatases are also involved in the sensitivity to oxidation, which probably contributes to the intrinsic sensitivity differences between various protein tyrosine phosphatases to oxidative inhibition 
(Groeger et al., 2009; Östman et al., 2011). The redox regulation of tyrosine phosphatases may depend on different oxidative stress conditions and the extent of oxidation, as it is tissue and differentiation dependent (Chiarugi et al., 2005). As mentioned above, the transient negative regulation of tyrosine phosphatases due to oxidants is dependent on ligand stimulation of the receptor tyrosine kinases.

Hydrogen peroxide is recognized as one of the main ROS capable of acting as a second messenger because of it is relative stability. Cytokines, growth factors and integrins activate the multicomponent NADPH oxidase enzymes as part of the receptor-mediated signaling in cells. Both superoxide and, hence, hydrogen peroxide are generated, with the latter serving a particularly significant role as a second messenger in signaling, which mediates the regulation of survival pathways in cells (Poole \& Nelson, 2008; Groeger et al., 2009).

The tyrosine phosphorylation level of a given protein is the result of the collective action of kinases and phosphatases. Signal transduction by ROS through reversible tyrosine phosphatase inhibition represents a widespread and conserved mechanism that is triggered by the ligand stimulation of receptor tyrosine kinases. Conformational changes lead to an increase in ROS production, which causes a transient negative regulation of protein tyrosine phosphatases that are associated with receptor tyrosine phosphatases, and at the same time decreases receptor tyrosine phosphatase dephosphorylation that leads to a high stimulation of its activity and signal propagation. The same PTP that suffered oxidation can be highly phosphorylated by the protein tyrosine kinase that is now activated. The oxidation of the active site of the tyrosine phosphatase protects the enzyme from autodephosphorylation. When the tyrosine phosphatase returns to the reduced form, its highly phosphorylated state influences a hyperactivation of the enzyme's activity, which is essential to terminating the signaling cascade in a fast way (Chiarugi \& Buricchi, 2007). This mechanism represents a strategy adopted by cells to promote receptor tyrosine kinase signaling by avoiding its prompt inactivation by tyrosine phosphatases. After the redox potential has been restabilized, tyrosine phosphatase recovers its activity and the signaling triggered by the receptor tyrosine kinases is terminated (Chiarugi et al., 2005; Chiarugi \& Buricchi, 2007). Thus, tyrosine kinase activation by oxidation is considered an indirect effect of tyrosine phosphatase inhibition. The overall mechanism is represented in figure 5.

The distinct but complementary function of kinases and phosphatases clarifies the role of both enzymes in controlling cellular signaling. Therefore, it is possible to affirm that kinases are implicated in controlling the amplitude of a signaling response whereas phosphatases are thought to have an important role in controlling the rate and duration of the response (Tonks, 2006).

A key element of a signaling response is reversibility. Regulated reversible phosphorylation of proteins and other cellular molecules plays a ubiquitous role in the control of cellular behavior. For oxidation to illustrate the mechanism for reversible regulation of protein tyrosine phosphatase function, it is essential that the active site cysteine residue not be oxidized to sulfinic or sulfonic acids, which is usually irreversible (Poole et al., 2004; Tonks, 2005). As mentioned elsewhere, thiol groups (SH) do not react at 
physiologically significant rates with a hydroperoxide, such as hydrogen peroxide, unless the reaction is catalyzed. However, thiolates $\left(\mathrm{S}^{-}\right)$react faster with hydroperoxides depending on their local environment (Forman et al., 2004). The reaction rate of hydrogen peroxide with protein tyrosine phosphatase is about $10^{5}$ times slower than with peroxiredoxin. The question appears on how hydrogen peroxide can react specifically with the active site of PTPs before its metabolization by enzymatic scavengers. Two possible mechanisms can arise:

1. Hydrogen peroxide is generated by NADPH oxidase close to PTP so that the concentration could be sufficient to cause enzyme modification; or

2. PTPs could be compartmentalized to the sites of ROS generation and far from scavenger enzymes (Chiarugi et al., 2005; Forman et al., 2004).

Besides, specificity of ROS to a given PTP may be influenced by contributions from the surrounding amino acids near the catalytic cysteine. The prevalence of basic amino acids near the active site of the enzyme can contribute to the extension formation of thiol ionization giving rise to thiolate anions within active cysteine. Chemical reactivity secondary to the local amino acids environments is likely to contribute to the modification of cysteine residues (Cross \& Templeton, 2006). This is the case of disulfide bonds or sulfenyl-amide conformations.

Receptor signaling in which receptor activation induces both the activation of downstream kinases and the oxidative inactivation of inhibitory phosphatases are components required for efficient signaling. The regulated and localized production of ROS can inactivate a subpopulation of phosphatase molecules near the site of ROS generation. The specificity of ROS for tyrosine phosphatase exists through different intrinsic sensitivities to oxidation and a tight control over the production of ROS. This production can be achieved by the controlled action of Nox enzymes, including their requirement for assembly into a multiprotein complex, the phosphorylation of regulatory subunits, the binding of inositol phospholipids and the small GTPase, Rac. In addition, regulation of Duox and NADPH oxidases by $\mathrm{Ca}^{2+}$ adds further control of ROS generation in cells (Tonks, 2006; Poole et al., 2004). As an example, Nox4 can regulate the oxidation of PTP1B in response to insulin and localizes with PTP1B on the intracellular membranes. Ecto-phosphatases, which are protein phosphatases that present a catalytic site facing the extracellular medium, are also able to respond to the endogenous production of hydrogen peroxide from mitochondria. The addition of a proton ionophore, which was able to reduce mitochondrial hydrogen peroxide production, was also shown to induce ectophosphatase activity due to the reduction of hydrogen peroxide outside of the cell (Cosentino-Gomes et al., 2009).

\section{Conclusion}

The mechanism by which ROS/RNS exerts a regulatory function in cysteine-based protein tyrosine phosphatases is well known, as well as the role of antioxidants in reverse enzyme oxidation. The reversible inhibition of tyrosine phosphatases by ROS has been intensely investigated in some diseases such as cancer and diabetes, but the complete pathway in which these reactive species are involved is not elucidated yet. Some questions still 
remain unsolved such as: How exactly ROS/RNS has a specific action on a given tyrosine phosphatase? Is there a compartmentalization of proteins involved in redox pathways? Is there a specific site of ROS/RNS production to induce redox signaling? How much of the total hydrogen peroxide generated in a specific site can be translated into a cellular signaling event? Which molecules would be involved in the redox sensor of the cell? The challenge to solve these questions seems to be very difficult, since we have multiple oxidants species from several sites of the cell. The development of specific probes for a given reactive specie, or for a particular site of ROS/RNS production would be of great contribution to understand the role of redox reactions in the regulation of physiological signaling process.

\section{References}

Alonso, A., Sasin, J., Bottini, N., Friedberg, I., Friedberg, I., Osterman, A., Godzik, A., Hunter, T., Dixon, J. \& Mustelin, T. (2004). Protein tyrosine phosphatases in the human genome. Cell, Vol. 117, No 6, pp. 699-711, ISSN 1097-4172

Antunes, F. \& Cadenas, E. (2000). Estimation of $\mathrm{H} 2 \mathrm{O} 2$ gradients across biomembranes. FEBS Letter, Vol. 475, No 2, pp. 121-126, ISSN 1873-3468

Bae, Y.S., Kang, S.W., Seo, M.S., Baines, I.C., Tekle, E., Chock, P.B. \& Rhee, S.G. (1997). Epidermal growth factor (EGF)-induced generation of hydrogen peroxide. Role in EGF receptor-mediated tyrosine phosphorylation. The Journal of Biological Chemistry, Vol. 272, No 1, pp. 217-221, ISSN 1083-351X

Barrett, W.C., DeGnore, J.P., König, S., Fales, H.M., Keng, Y.F., Zhang, Z.Y., Yim, M.B. \& Chock, P.B. (1999). Regulation of PTP1B via glutathionylation of the active site cysteine 215. Biochemistry, Vol. 38, No 20, pp. 6699-6705, ISSN 1520-4995

Biteau, B. Labarre, J. \& Toledano, M.B. (2003). ATP-dependent reduction of cysteinesulphinic acid by S. cerevisiae sulphiredoxin. Nature, Vol. 425, No 6961, pp. 980-984, ISSN 1476-4687

Blume-Jensen, P. \& Hunter, T. (2001). Oncogenic kinase signalling. Nature, Vol. 411, No 6835, PP. 355-365, ISSN 1476-4687

Brandes, N., Schmitt, S. \& Jakob, U. (2009). Thiol-based redox switches in eukaryotic proteins. Antioxidants \& Redox Signaling, Vol. 11, No 5, pp. 997-1014, ISSN 15577716

Chen, C.Y., Willard, D. \& Rudolph, J. (2009). Redox regulation of SH2-domain-containing protein tyrosine phosphatases by two backdoor cysteines. Biochemistry, Vol 48, No 6, pp. 1399-1409, ISSN 1520-4995

Chen, K., Craige, S.E. \& Keaney Jr., J.F. (2009). Downstream targets and intracellular compartmentalization in Nox Signaling. Antioxidants \& Redox Signaling, Vol. 11, No 10, pp. 2467-2480, ISSN 1557-7716

Chiarugi, P. \& Buricchi, F. (2007). Protein tyrosine phosphorylation and reversible oxidation: two cross-talking posttranslation modifications. Antioxidants \& Redox Signaling, Vol. 9, No 1, PP.1-24, ISSN 1557-7716

Chiarugi, P., Fiaschi, T., Taddei, M.L., Talini, D., Giannoni, E., Raugei, G. \& Ramponi, G. (2001). Two vicinal cysteines confer a peculiar redox regulation to low molecular weight protein tyrosine phosphatase in response to platelet-derived growth factor 
receptor stimulation. The Journal of Biological Chemistry, Vol. 276, No 36, pp. 3347833487, ISSN 1083-351X

Chiarugi, P., Taddei, M.L. \& Ramponi, G. (2005). Oxidation and tyrosine phosphorylation: synergistic or antagonistic cues in protein tyrosine phosphatase. Cellular and Molecular Life Sciences, Vol. 62, No 9, PP. 931-936, ISSN 1420-9071

Cosentino-Gomes, D., Russo-Abrahão, T., Fonseca-de-Souza, A.L., Ferreira, C.R., Galina, A. \& Meyer-Fernandes, J.R. (2009). Modulation of Trypanosoma rangeli ectophosphatase activity by hydrogen peroxide. Free Radical Biology and Medicine, Vol. 47, No 2, pp. 152-158, ISSN 1873-4596

Cross, J.V. \& Templeton, D.J. (2006). Regulation of signal transduction through protein cysteine oxidation. Antioxidants \& Redox Signaling, Vol. 8, No 9-10, pp. 1819-1827, ISSN 1557-7716

den Hertog, J., Groen, A. \& van der Wijk, T. (2005). Redox regulation of protein-tyrosine phosphatases. Archives of Biochemistry and Biophysics, Vol. 434, No 1, pp. 11-15, ISSN 1096-0384

den Hertog, J., Tracy, S. \& Hunter, T. (1994). Phosphorylation of receptor protein-tyrosine phosphatase alpha on Tyr789, a binding site for the SH3-SH2-SH3 adaptor protein GRB-2 in vivo. The EMBO Journal, Vol. 13, No 13, pp. 3020-3032, ISSN 1460-2075

Denu, J.M. \& Dixon, J.E. (1998). Protein tyrosine phosphatases: mechanisms of catalysis and regulation. Current Opinion in Chemical Biology, Vol. 2, No 5, pp.633-641, ISSN 18790402

Denu, J.M. \& Tanner, K.G. (1998). Specific and reversible inactivation of protein tyrosine phosphatases by hydrogen peroxide: evidence for a sulfenic acid intermediate and implications for redox regulation. Biochemistry, Vol. 37, No 16, pp. 5633-5642, ISSN 1520-4995

Do, K.Q., Benz, B., Grima, G., Gutteck-Amsler, U., Kluge, I. \& Salt, T.E. (1996). Nitric oxide precursor arginine and S-nitrosoglutathione in synaptic and glial function. Neurochemistry International, Vol. 29, No 3, pp. 213-224, ISSN 1872-9754

Dröge, W. (2002). Free radicals in the physiological control of cell function. Physiological Reviews, Vol. 82, No 1, pp. 47-95, ISSN 1522-1210

Forman, H.J., Zhanq, H. \& Rinna, A. (2009). Glutathione: overview of its protective roles, measurement, and biosynthesis. Molecular Aspects of Medicine, Vol. 30, No 1-2, pp. 112, ISSN 1872-9452

Forman, H.J.m Fukuto, J.M. \& Torres, M. (2004). Redox signaling: thiol chemistry defines which reactive oxygen and nitrogen species can act as second messengers. American Journal of Physiology, Vol. 287, No 2, pp. 246-256, ISSN 1522-1563

Giannoni, E., Buricchi, F., Raugei, G., Ramponi, G. \& Chiarugi, P. (2005). Intracellular reactive oxygen species activate Src tyrosine kinase during cell adhesion and anchorage-dependent cell growth. Molecular and Cellular Biology, Vol. 25, No 15, PP. 6391-6403, ISSN 1098-5549

Groeger, G., Quiney, C. \& Cotter, T.G. (2009). Hydrogen peroxide as a cell-survival signaling molecule. Antioxidants \& Redox Signaling, Vol. 11, No 11, PP. 2655-2671, ISSN 15577716 
Harrison, R. (2002). Structure and function of xanthine oxidoreductase: where are we now? Free Radical Biology and Medicine, Vol. 33, No 6, pp. 774-797, ISSN 1873-4596

Hess, D.T., Matsumoto, A., Kim, S.O. Marshall, H.E. \& Stamler, J.S. (2005). Protein Snitrosylation: purview and parameters. Nature Reviews. Molecular Cell Biology, Vol. 6, No 2, pp. 150-166, ISSN 1471-0080

Janssen-Heininger, Y.M.W., Mossman, B.T., Heintz, N.H., Forman, H.J., Kalyanaraman, B., Finkel T., Stamler, J.S., Rhee, S.G. \& Van der Vliet, A. (2008). Redox-based regulation of signal transduction: principles, pitfalls, and promises. Free Radical Biology \& Medicine, Vol. 45, No 1, pp. 1-17, ISSN 1873-4596

Jia, Z., Barford, D., Flint, A.J. \& Tonks, N.K. (1995). Structural basis for phosphotyrosine peptide recognition by protein tyrosine phosphatase 1B. Science, Vol. 268, No 5218, pp. 1754-1758, ISSN 1095-9203

Kim, C., Kim, J.Y. \& Kim, J.H. (2008) Cytosolic phospholipase A(2), lipoxygenase metabolites, and reactive oxygen species. BMB reports, Vol. 41, No 8, pp. 555-559, ISSN 1976-670X

Kolmodin, K. \& Aqvist J. (2001). The catalytic mechanism of protein tyrosine phosphatases revisited. FEBS Letter, vol. 498, No.2-3, pp. 208-213, ISSN 1873-3468

Kwon, J., Lee, S.R., Yang, K.S., Ahn, Y., Kim, Y.J., Stadtman, E.R. \& Rhee, S.G. (2004). Reversible oxidation and inactivation of the tumor suppressor PTEN in cells stimulated with peptide growth factors. Proceedings of the National Academy of Sciences of the United States of America, Vol. 101, No 47, pp. 16419-16424, ISSN 10916490

Lambeth, J.D. (2002). Nox/Duox family of nicotinamide adenine dinucleotide (phosphate) oxidases. Current Opinion in Hematology, Vol. 9, No 1, pp. 11-17, ISSN 1531-7048

Lee, S.R., Kwon, K.S., Kim, S.R. \& Rhee, S.G. (1998). Reversible inactivation of proteintyrosine phosphatase $1 \mathrm{~B}$ in A431 cells stimulated with epidermal growth factor. The Journal of Biological Chemistry, Vol. 273, No 25, pp. 15366-15372, ISSN 1083-351X

Lee, S.R., Yang, K.S., Kwon, J., Lee, C., Jeong, W. \& Rhee, S.G. (2002). Reversible inactivation of the tumor suppressor PTEN by H2O2. The Journal of Biological Chemistry, Vol. 277, No 23, pp. 20336-20342, ISSN 1083-351X

Makino, N., Sasaki, K., Hashida, K. \& Sakakura, Y. (2004). A metabolic model describing the $\mathrm{H} 2 \mathrm{O} 2$ elimination by mammalian cells including $\mathrm{H} 2 \mathrm{O} 2$ permeation through cytoplasmic and peroxisomal membranes: comparison with experimental data. Biochimica et Biophysica Acta, Vol. 1673, No 3, PP. 149-159, ISSN 0006-3002

Mayer, B.J. (2008). Clues to the evolution of complex signaling machinery. Proceedings of the National Academy of Sciences of the United States of America, vol. 105, No 28, pp. 94539454, ISSN 1091-6490

McCord, J.M. \& Fridovich, I. (1969). The utility of superoxide dismutase in studying free radical reactions. I. Radicals generated by the interaction of sulfite, dimethyl sulfoxide, and oxygen. The Journal of Biological Chemistry, Vol. 244, No 22, pp. 60566063, ISSN 1083-351X

Meng, T.C., Fukada, T. \& Tonks, N.K. (2002). Reversible oxidation and inactivation of protein tyrosine phosphatases in vivo. Molecular Cell, Vol. 9, No 2, pp. 387-399, ISSN 1097-4164 
Mittal, C.K. \& Murad, F. (1977). Properties and oxidative regulation of guanylate cyclase. Journal of Cyclic Nucleotide Research, Vol. 3, No 6, pp. 381-391, ISSN 0095-1544

Östman, A., Frijhoff, J., Sandin, A. \& Böhmer, F.D. (2011). Regulation of protein tyrosine phosphatases by reversible oxidation. Journal of Biochemistry, in press, ISSN 17562651

Pontremoli, S., Traniello, S., Enser, M., Shapiro, S. \& Horecker, B.L. (1967). Regulation of fructose diphosphatase activity by disulfide exchange. Proceedings of the National Academy of Sciences of the United States of America, Vol. 58, No 1, pp. 286-293, ISSN 1091-6490

Poole, L.B., Karplus, P.A. \& Claiborne, A. (2004). Protein sulfenic acids in redox signaling. Annual review of pharmacology and toxicology, Vol. 44, No 325, pp. 325-347, ISSN 1545-4304

Poole, L.B. \& Nelson, K.J. (2008). Discovering mechanisms of signaling-mediated cysteine oxidation. Current Opinion in Chemical Biology, Vol. 12, No 1, pp. 18-24, ISSN 18790402

Rhee, S.G., Chang, T.S., Bae, Y.S., Lee, S.R. \& Kang, S.W. (2003). Cellular regulation by hydrogen peroxide. Journal of the American Society of Nephrology, Vol. 14, No 8, pp. 211-215, ISSN 1533-3450

Salmeen, A. \& Barford, D. (2005). Functions and mechanisms of redox regulation of cysteine-based phosphatases. Antioxidants \& Redox Signaling, Vol. 7, No 5-6, PP.560577, ISSN 1557-7716

Seaver, L.C. \& Imlay, J.A. (2001). Hydrogen peroxide fluxes and compartmentalization inside growing Escherichia coli. Journal of Bacteriology, Vol. 183, No 24, pp. 71827189, ISSN1098-5530

Spickett, C.M., Pitt, A.R., Morrice, N. \& Kolch, W. (2006). Proteomic analysis of phosphorylation, oxidation and nitrosylation in signal transduction. Biochimica et Biophysica Acta, Vol. 1764, No 12, PP. 1823-1841, ISSN 0006-3002

Sundaresan, M., Yu, Z.X., Ferrans, V.J., Irani, K. \& Finkel, T. (1995). Requirement for generation of $\mathrm{H} 2 \mathrm{O} 2$ for platelet-derived growth factor signal transduction. Science, Vol. 270, No 5234, pp. 296-299, ISSN 1095-9203

Tabernero, L., Aricescu, A.R., Jones, E.Y. \& Szedlacsek, S.E. (2008). Protein tyrosine phosphatases: structure-function relationships. The FEBS Journal, Vol. 275, No 5, pp. 867-882, ISSN 1742-4658

Tiganis, T. \& Bennett, A.M. (2007). Protein tyrosine phosphatase function: the substrate perspective. The Biochemical Journal, Vol. 402, No 1, PP.1-15.

Tonks, N.K. (2005). Redox redux: revisiting PTPs and the control of cell signaling. Cell, Vol. 121, No 5, pp. 667-670, ISSN 1097-4172

Tonks, N.K. (2006). Protein tyrosine phosphatases: from genes, to function, to disease. Nature Reviews Molecular Cell Biology, Vol. 7, No 11, PP. 833-846, ISSN 1471-0080

Torres, M. (2003). Mitogen-activated protein kinase pathways in redox signaling. Frontiers in Bioscience, Vol. 1, No 8, pp. 369-391, ISSN 1093-4715

Woo, H.A., Chae, H.Z., Hwang, S.C., Yang, K.S., Kang, S.W., Kim, K. \& Rhee, S.G. (2003). Reversing the inactivation of peroxiredoxins caused by cysteine sulfinic acid formation. Science, Vol. 300, No 5619, pp. 653-656, ISSN 1095-9203 
Zhao, Z., Larocque, R., Ho, W.T., Fischer, E.H. \& Shen, S.H. (1994). Purification and characterization of PTP2C, a widely distributed protein tyrosine phosphatase containing two SH2 domains. The Journal of Biological Chemistry, Vol. 269, No 12, pp. 8780-8785, ISSN 1083-351X 


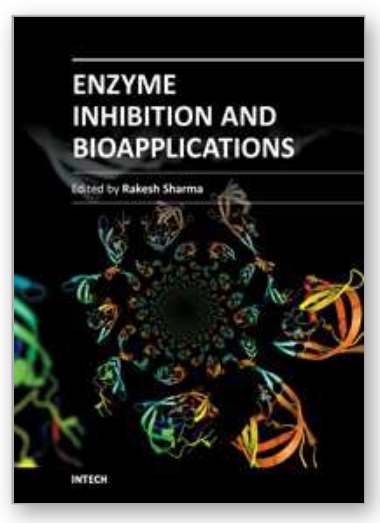

\author{
Enzyme Inhibition and Bioapplications \\ Edited by Prof. Rakesh Sharma
}

ISBN 978-953-51-0585-5

Hard cover, 314 pages

Publisher InTech

Published online 09, May, 2012

Published in print edition May, 2012

Enzyme Inhibition and Bioapplications is a concise book on applied methods of enzymes used in drug testing. The present volume will serve the purpose of applied drug evaluation methods in research projects, as well as relatively experienced enzyme scientists who might wish to develop their experiments further. Chapters are arranged in the order of basic concepts of enzyme inhibition and physiological basis of cytochromes followed by new concepts of applied drug therapy; reliability analysis; and new enzyme applications from mechanistic point of view.

\title{
How to reference
}

In order to correctly reference this scholarly work, feel free to copy and paste the following:

Daniela Cosentino-Gomes and José Roberto Meyer-Fernandes (2012). Reversible Inhibition of Tyrosine Protein Phosphatases by Redox Reactions, Enzyme Inhibition and Bioapplications, Prof. Rakesh Sharma (Ed.), ISBN: 978-953-51-0585-5, InTech, Available from: http://www.intechopen.com/books/enzyme-inhibition-andbioapplications/reversible-inhibition-of-tyrosine-protein-phosphatases-by-redox-reactions

\section{INTECH}

open science | open minds

\section{InTech Europe}

University Campus STeP Ri

Slavka Krautzeka 83/A

51000 Rijeka, Croatia

Phone: +385 (51) 770447

Fax: +385 (51) 686166

www.intechopen.com

\section{InTech China}

Unit 405, Office Block, Hotel Equatorial Shanghai

No.65, Yan An Road (West), Shanghai, 200040, China

中国上海市延安西路65号上海国际贵都大饭店办公楼 405 单元

Phone: +86-21-62489820

Fax: +86-21-62489821 
(C) 2012 The Author(s). Licensee IntechOpen. This is an open access article distributed under the terms of the Creative Commons Attribution 3.0 License, which permits unrestricted use, distribution, and reproduction in any medium, provided the original work is properly cited. 